\title{
Acute liver injury in the context of immune checkpoint inhibitor-related colitis treated with infliximab
}

\author{
Hao Chi Zhang ${ }^{1}$, Wenyi Luo ${ }^{2}$ and Yinghong Wang ${ }^{3^{*}}$ [D
}

\begin{abstract}
Background: Immune checkpoint inhibitors (ICPIS), used to treat different advanced malignancies, are associated with a wide range of immune-related adverse reactions (irAEs) that deserve close monitoring of patients. Gastrointestinal reactions and hepatotoxicity may occur, which warrant careful evaluation to confirm the etiology and attribution to ICPIs as these events could affect future management.

Case presentation: We describe a case of a patient with prostate adenocarcinoma, treated with dual ICPIs comprised of ipilimumab and nivolumab, who developed elevated liver enzymes in the context of infliximab therapy prescribed to treat gastrointestinal irAE from his ICPIs. The patient's grade 3 colitis became steroid-refractory, requiring a one-time infusion of infliximab, a biologic agent used commonly in inflammatory bowel disease, as a rescue therapy, to which he responded. The patient subsequently developed liver injury. This presented a diagnostic dilemma involving differential diagnoses of hepatotoxicity due to ICPI or infliximab exposure. A careful review of the clinical history, evaluation of the chronology of events, and exclusion of other causes of acute hepatitis were employed to make the final diagnosis of this event as infliximab-associated hepatotoxicity.

Conclusion: ICPIs such as CTLA-4 and PD-1 inhibitors have the potential to cause both gastrointestinal reactions and hepatotoxicity. An additional confounding factor in our patient's case was the exposure to infliximab used to manage an established irAE that developed after the last exposure to ICPIs. The clinical history and data supported infliximab-associated hepatotoxicity, rather than an irAE. With the increasing application of ICPIs for different cancers, in conjunction with potential risks for irAE, the liver profile should be closely monitored during treatment with ICPI as well as with anti-TNF-a agents in this patient population.
\end{abstract}

Keywords: prostate cancer, immune checkpoint inhibitors, infliximab, liver injury

\section{Background}

Immune checkpoint inhibitors (ICPIs) such as ipilimumab, a CTLA-4 inhibitor, and nivolumab, a PD-1 inhibitor, are more widely used to treat various types of cancers, but they can also be associated with immune-related adverse reactions (irAEs) including enterocolitis, hepatitis, or skin rash. Careful attribution of irAEs is important as it may impact the patient's subsequent cancer therapy. The development of liver injury secondary to ICPI administration is infrequent but well-known and reported. The use of infliximab

\footnotetext{
* Correspondence: ywang59@mdanderson.org

${ }^{3}$ Department of Gastroenterology, Hepatology and Nutrition, The University of Texas MD Anderson Cancer Center, 1515 Holcombe Blvd., Unit 1466, Houston, TX 77030, USA

Full list of author information is available at the end of the article
}

as an agent for steroid-refractory colitis secondary to ICPI has been reported and potentially effective. However, infliximab is also associated with hepatotoxicity. We describe a case with a complicated history that prompted careful analysis of the differential diagnoses for acute liver injury presented with new elevation in liver enzymes.

\section{History of present illness}

A 79-year-old man with a history of metastatic prostate adenocarcinoma, treated with ICPIs ipilimumab and nivolumab, and enterocolitis as irAE treated with infliximab, was evaluated for new elevation in liver enzymes and bilirubin.

The patient had a past medical history including essential hypertension and hypertriglyceridemia. He recently recovered from influenza A H3 virus infection. 
He was also treated for a skin rash which was deemed to be an adverse event from ICPI. Otherwise, there was no history of chronic liver disease or diabetes. Prior imaging of the abdomen before exposure to ipilimumab and nivolumab did not reveal evidence of hepatosteatosis. He consumed alcohol weekly, including three glasses of wine and one can of beer per week. Family history included colon cancer of the patient's father and brother.

Previous management of his prostate cancer involved neoadjuvant chemotherapy with temsirolimus during the initial year of diagnosis 13 years prior, followed by radical prostatectomy and pelvic lymph node dissection. He underwent intermittent androgen deprivation therapy with leuprolide within a year after diagnosis, during which time he was diagnosed with pelvic lymph node metastasis in 5 years thereafter. Given pelvic and right femur metastases, he underwent palliative radiotherapy to the right femur. He was also treated with a period of abiraterone acetate with prednisone before this presentation during the same year. As he had demonstrated progression of disease, ICPIs were initiated.

The patient underwent institutional Phase 2 protocol treatment (2016-0848) with combination regimen of ipilimumab $1 \mathrm{mg} / \mathrm{kg}$ and nivolumab $3 \mathrm{mg} / \mathrm{kg}$ (for body weight of $73 \mathrm{~kg}$ ), starting just over 4 months prior to this presentation (Fig. 1). The second cycle was administered 9 weeks after the first cycle, and the third cycle was administered 3 weeks thereafter (Fig. 1). Shortly after the third cycle, the patient began to suffer from loose bowel movements, progressing to acute frequent non-bloody diarrhea characterized as four episodes during the day and up to twelve nocturnal episodes. This diarrhea was also associated with anterior abdominal discomfort and acute acid reflux symptoms. Due to concern for grade 3 irAE of diarrhea/colitis, the patient's ICPIs were discontinued at that point.

\section{Evaluation of gastrointestinal irAE}

A contrast-enhanced computed tomography $(\mathrm{CT})$ of the abdomen and pelvis at the time showed evidence of mild wall thickening of the distal ileal loops, and stable finding of prior small low-attenuation liver lesions thought to be cysts, without biliary ductal dilatation. Clostridium difficile testing and gastrointestinal enteric pathogen testing were negative for infectious causes of diarrhea. Fecal calprotectin was elevated at $484 \mu \mathrm{g} / \mathrm{g}$ (reference range: $\leq 50 \mu \mathrm{g} / \mathrm{g})$.

An upper endoscopy revealed small erosions in the distal gastric body and pre-pyloric region, normal-appearing duodenum, and no gastroesophageal varices; biopsies revealed duodenitis and chronic inflammation in the stomach. Ileo-colonoscopy revealed mild erythema of the terminal ileum as well as mild to moderate erythema in the entire colonic mucosa with normal-appearing rectum; biopsies revealed diffuse chronic mucosa injury and increased apoptosis (Fig. 2), most compatible with ICPI-associated enterocolitis. No further ipilimumab or nivolumab was given to this patient.

\section{Hepatotoxicity event}

For management of gastrointestinal irAE, high-dose intravenous methylprednisolone $(1 \mathrm{mg} / \mathrm{kg}$ twice daily, for body weight of $67 \mathrm{~kg}$ ) was started (Fig. 1), leading to mild improvement in diarrhea after 3 days. The steroid

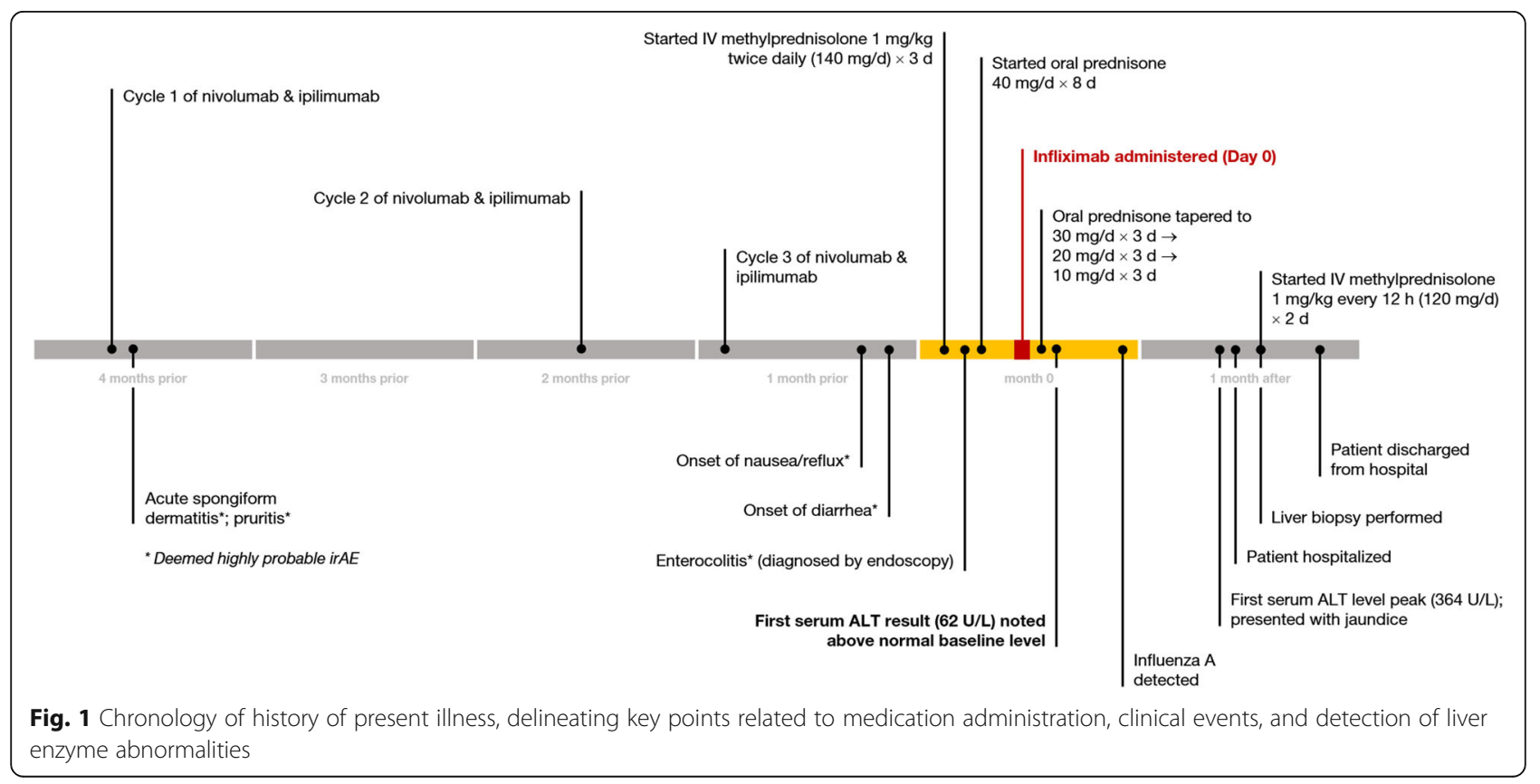




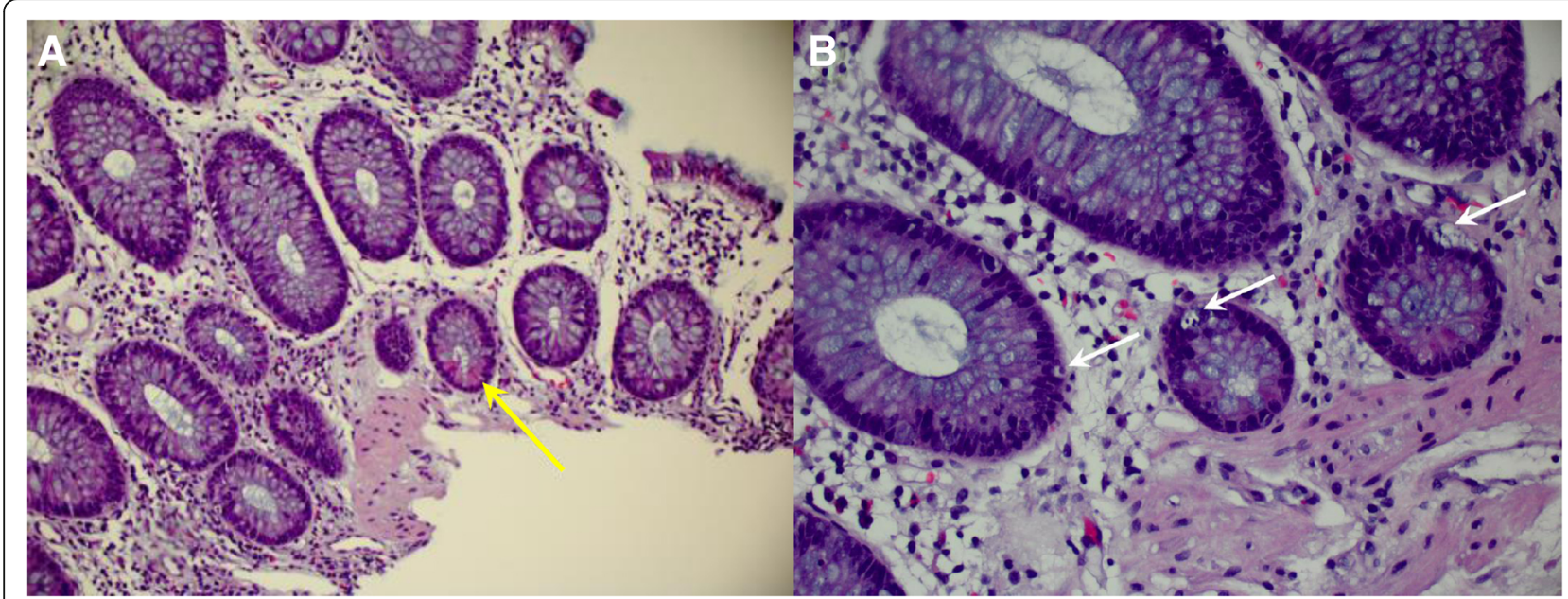

Fig. 2 Biopsies from colonic mucosa. Panel a: (Hematoxylin and eosin stain, 20x) Paneth cell metaplasia (yellow arrow). Panel b (Hematoxylin and eosin stain, 40x) Increased apoptosis (white arrows)

regimen was then transitioned to prednisone $40 \mathrm{mg} / \mathrm{d}$ for the next 8 days (Fig. 1).

The patient's liver biochemical testing after brief hospitalization prior to discharge included serum ALT $35 \mathrm{U} / \mathrm{L}$ (reference range: 7-56 U/L), AST $32 \mathrm{U} / \mathrm{L}$ (reference range: 15-46 U/L), alkaline phosphatase (ALP) 60 $\mathrm{U} / \mathrm{L}$ (reference range: $38-126 \mathrm{U} / \mathrm{L}$ ), total bilirubin 0.4 $\mathrm{mg} / \mathrm{dL}$ (reference range: $0.2-1.3 \mathrm{mg} / \mathrm{dL}$ ), albumin $2.8 \mathrm{~g} /$
dL (reference range: $3.5-4.7 \mathrm{~g} / \mathrm{dL}$ ), and INR 1.06 (reference range: 0.9-1.2) (Fig. 3; Fig. 4).

However, just 4 days after discharge from the hospital, there was recurrence of worsening diarrhea associated with nausea and emesis despite being on prednisone 40 $\mathrm{mg} / \mathrm{d}$, which raised the concern for steroid-refractory ICPI-associated enterocolitis. Anti-tumor necrosis factor (anti-TNF) biologic therapy, infliximab $(5 \mathrm{mg} / \mathrm{kg})$, was

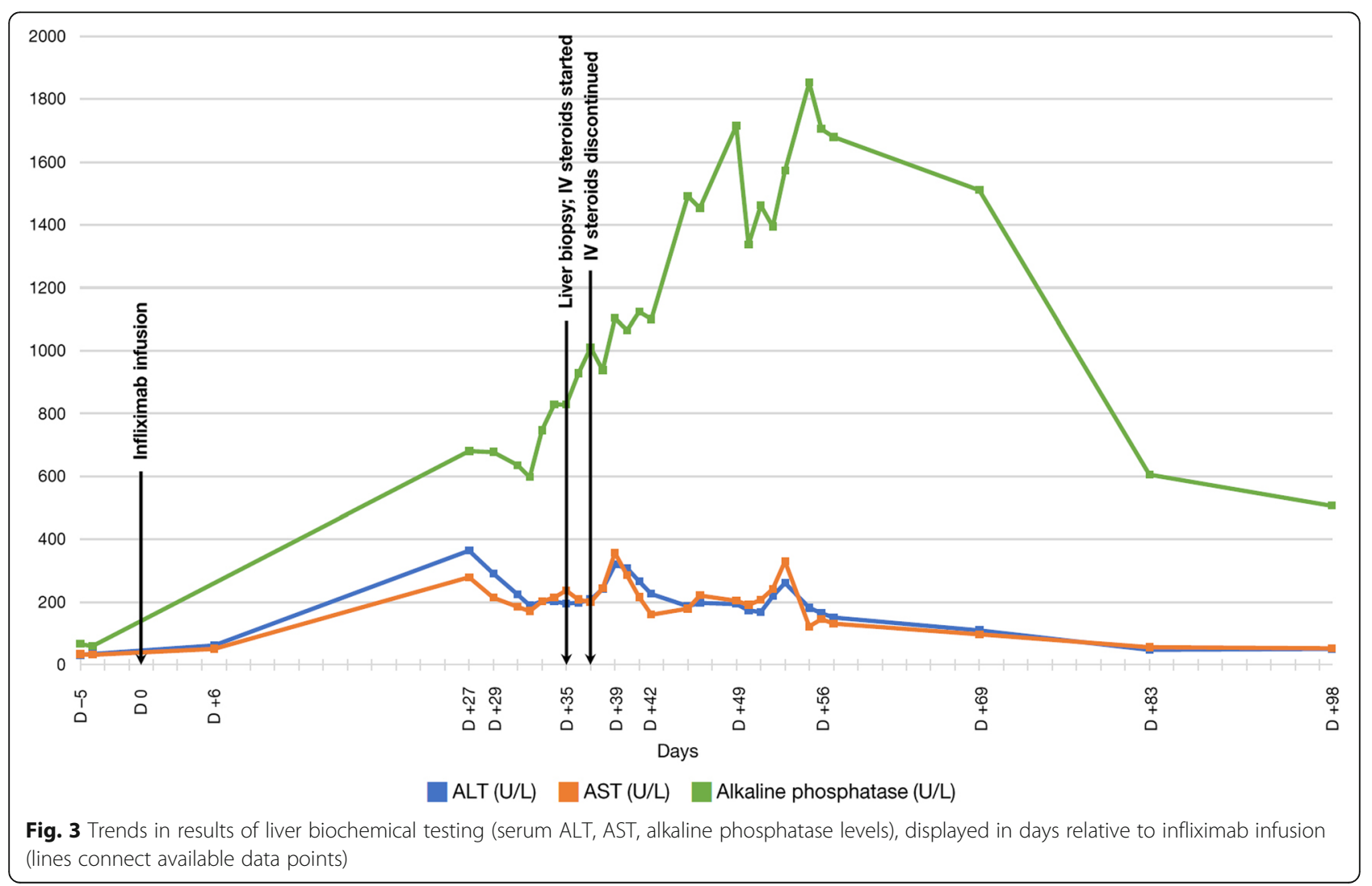




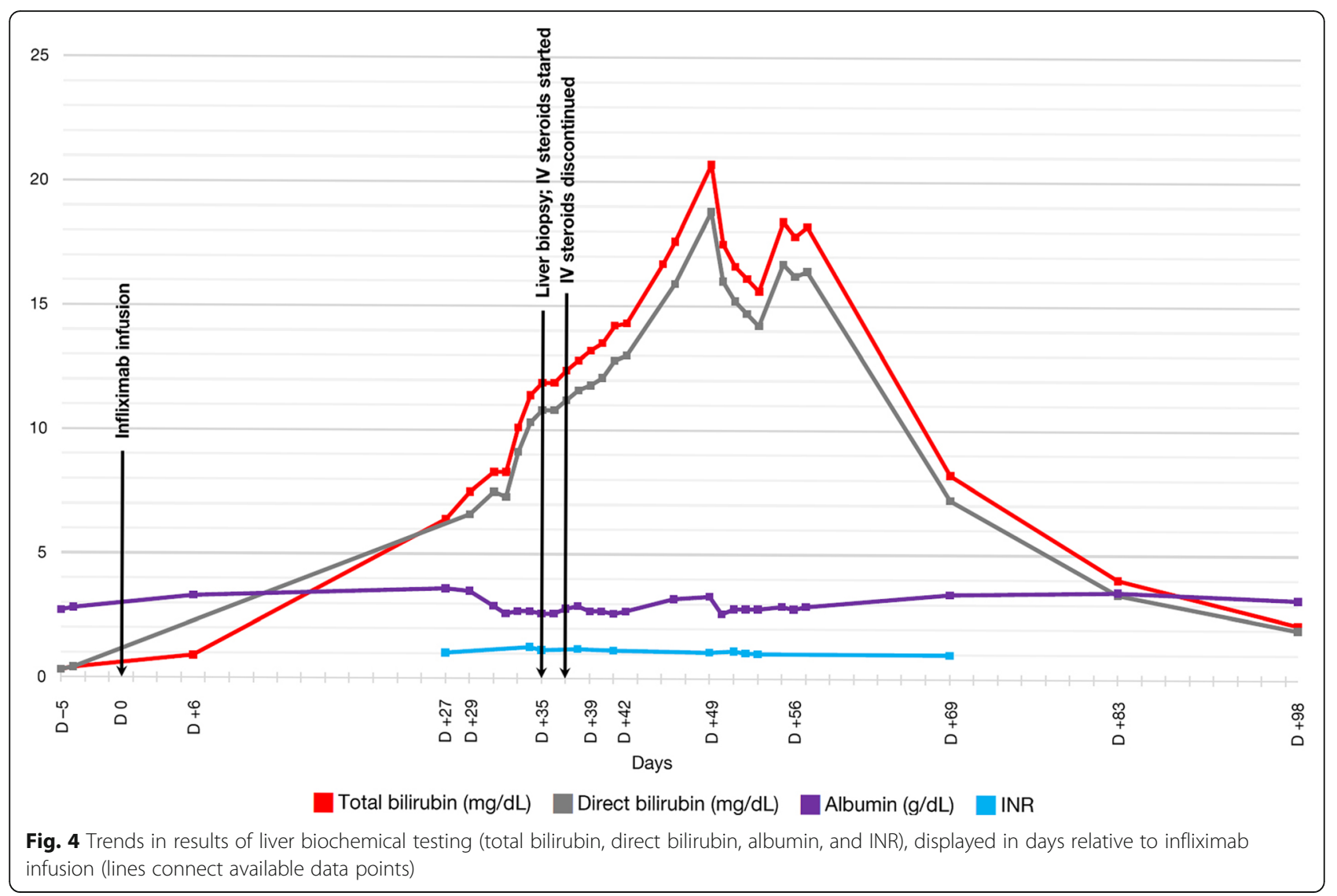

administered once. After completion of a total of 8 days of prednisone $40 \mathrm{mg} / \mathrm{d}$, a steroid taper regimen was implemented from prednisone $30 \mathrm{mg} / \mathrm{d}$ for 3 days, $20 \mathrm{mg} / \mathrm{d}$ for 3 days, and $10 \mathrm{mg} / \mathrm{d}$ for 3 days (Fig. 1).

Outpatient labs obtained 6 days after the infliximab administration revealed interval change in liver profile, with increase in serum ALT to $62 \mathrm{U} / \mathrm{L}$, AST to $51 \mathrm{U} / \mathrm{L}$, and total bilirubin to $0.9 \mathrm{mg} / \mathrm{dL}$ (Fig. 3; Fig. 4).

At 29 days after the initial infliximab administration, the patient presented to the emergency room with new-onset jaundice without abdominal pain, nausea, emesis, or fever. Liver enzymes from 2 days prior to this presentation showed abrupt elevations, with serum ALT 364 U/L, AST $279 \mathrm{U} / \mathrm{L}$, ALP $680 \mathrm{U} / \mathrm{L}$, and total bilirubin $6.4 \mathrm{mg} / \mathrm{dL}$. Repeat lab testing in the emergency room showed ALT 291 U/L, AST 214 U/L, ALP $677 \mathrm{U} / \mathrm{L}$, total bilirubin $7.5 \mathrm{mg} / \mathrm{dL}$, direct bilirubin $6.6 \mathrm{mg} / \mathrm{dL}$, and albumin $3.5 \mathrm{~g} / \mathrm{dL}$ (Fig. 3; Fig. 4). The patient did not report significant acetaminophen use or introduction of new medications.

On physical examination, he had a temperature of $37.4{ }^{\circ} \mathrm{C}$, pulse of 80 beats per minute, blood pressure of $119 / 65 \mathrm{mmHg}$, respiratory rate of $16 / \mathrm{min}$, and normal oxygenation on ambient air. His weight was $63 \mathrm{~kg}$ with a BMI $22.6 \mathrm{~kg} / \mathrm{m}^{2}$. He exhibited conjunctival icterus and jaundice of the skin. The abdomen was soft without tenderness or hepatosplenomegaly. There were no stigmata of chronic or advanced liver disease. He had no signs of hepatic encephalopathy.

Lab testing for liver disease were performed (Table 1). Anti-nuclear antibody titer, anti-smooth muscle antibody, anti-liver-kidney-microsomal antibody were negative. Active viral hepatitides $\mathrm{A}, \mathrm{B}, \mathrm{C}$, and $\mathrm{E}$ were excluded. CMV IgG was previously positive prior to infliximab administration, with subsequent IgM testing that was equivocal; testing for EBV IgM was negative with positive nuclear antigen and IgG; and testing for HSV-1 and HSV-2 (quantitative assays) were negative (undetectable viral load). HFE gene testing revealed one mutation of H63D, which was not deemed clinically significant. Additional lab results are reported in Table 1.

\section{Evaluation of liver toxicity}

A second CT of the abdomen and pelvis with oral and intravenous contrast demonstrated normal ileum and no major significant changes except slight increase in a sub-centimeter hypodensity in the right liver. Magnetic resonance imaging of the abdomen with magnetic resonance cholangiopancreatography showed no intrahepatic or extrahepatic biliary duct dilatation, and stable sub-centimeter densities in the liver.

Due to persistent elevation of liver enzymes at 5 weeks from infliximab administration, a non-targeted liver 
Table 1 Laboratory data

\begin{tabular}{|c|c|c|}
\hline Variable & $\begin{array}{l}\text { Reference Range, } \\
\text { Adults }^{\mathrm{a}}\end{array}$ & Result \\
\hline $\begin{array}{l}\text { White blood cell count (per } \\
\mu \mathrm{L} \text { ) }\end{array}$ & $4000-11,000$ & 5200 \\
\hline Hemoglobin (g/dL) & $14.0-18.0$ & 13.0 \\
\hline Mean corpuscular volume (fL) & $82-98$ & 87 \\
\hline Platelet count (per $\mu \mathrm{L}$ ) & $140,000-440,000$ & 208,000 \\
\hline Sodium (mEq/L) & $136-145$ & 143 \\
\hline Blood urea nitrogen $(\mathrm{mg} / \mathrm{dL})$ & $8-20$ & 16 \\
\hline Creatinine (mg/dL) & $0.70-1.30$ & 1.19 \\
\hline Lactate dehydrogenase (U/L) & $313-618$ & 870 \\
\hline Hepatitis A IgM antibody & Negative & Negative \\
\hline Hepatitis B surface antigen & Non-reactive & Non-reactive \\
\hline $\begin{array}{l}\text { Hepatitis B surface antibody } \\
(\mathrm{mlU} / \mathrm{mL})\end{array}$ & $<5.0$ (Negative) & $<5.0$ (Negative) \\
\hline $\begin{array}{l}\text { Hepatitis B total core } \\
\text { antibody }\end{array}$ & Non-reactive & Non-reactive \\
\hline Hepatitis B DNA (IU/mL) & Undetected & Undetected \\
\hline Hepatitis C antibody & Non-reactive & Non-reactive \\
\hline Hepatitis E IgM antibody & Negative & Negative \\
\hline Hepatitis E IgG antibody & Negative & Positive \\
\hline CMV IgM (units) & $0.0-0.9$ & 0.9 (Equivocal) \\
\hline CMV lgG (units) & $0.00-0.79$ & 11.90 \\
\hline $\begin{array}{l}\text { EBV viral capsid antigen lgM } \\
\text { antibody }\end{array}$ & Negative & Negative \\
\hline $\begin{array}{l}\text { EBV viral capsid antigen lgG } \\
\text { antibody }\end{array}$ & Negative & Positive \\
\hline $\begin{array}{l}\text { EBV nuclear antigen IgG } \\
\text { antibody }\end{array}$ & Negative & Positive \\
\hline HSV-1 DNA (copies/mL) & Not detected & Not detected \\
\hline HSV-2 DNA (copies/mL) & Not detected & Not detected \\
\hline Anti-nuclear antibody titer & $<1: 40$ & $<1: 40$ \\
\hline Anti-smooth muscle antibody & Negative & Negative \\
\hline Anti-mitochondrial antibody & Negative & Negative \\
\hline $\begin{array}{l}\text { Anti-liver kidney microsomal } \\
\text { type } 1 \text { antibody }\end{array}$ & Negative & Negative \\
\hline Ceruloplasmin (mg/dL) & $19.0-31.0$ & 30.5 \\
\hline Ferritin $(\mathrm{ng} / \mathrm{mL})$ & $30-400$ & 638 \\
\hline Iron $(\mu \mathrm{g} / \mathrm{dL})$ & $49-181$ & 51 \\
\hline $\begin{array}{l}\text { Total iron binding capacity } \\
(\mu \mathrm{g} / \mathrm{dL})\end{array}$ & $250.0-450.0$ & 247.7 \\
\hline HFE gene mutation analysis & - & $\begin{array}{l}\text { One copy of H63D } \\
\text { detected }\end{array}$ \\
\hline Triglycerides (mg/dL) & $<150$ & $166^{\mathrm{b}}$ \\
\hline LDL-cholesterol (mg/dL) & $<100$ & $74^{b}$ \\
\hline $\begin{array}{l}\text { Anti-tissue transglutaminase } \\
\text { IgA antibody }(\mathrm{U} / \mathrm{mL})\end{array}$ & $<4.0$ & $<1.2$ \\
\hline $\begin{array}{l}\text { Anti-tissue transglutaminase } \\
\operatorname{lgG} \text { antibody }(\mathrm{U} / \mathrm{mL})\end{array}$ & $<6.0$ & $<1.2$ \\
\hline
\end{tabular}

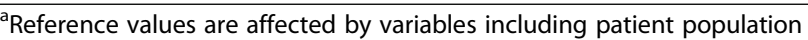
and laboratory methods employed

${ }^{\mathrm{b}}$ These results were obtained over 1 year prior to presentation biopsy was performed that demonstrated cholestatic hepatitis with bile duct injury, cholestasis, mixed steatosis but predominantly microvesicular steatosis (Fig. 5). There were findings of mixed inflammatory infiltrates, mild portal and periportal fibrosis, and no iron or $\alpha-1$ antitrypsin cytoplasmic globules.

Intravenous methylprednisolone $1 \mathrm{mg} / \mathrm{kg}$ every $12 \mathrm{~h}$ were initiated for $48 \mathrm{~h}$ before discontinuation upon recognition of histology findings and lack of improvement of liver enzymes. By exclusion of other etiologies, and occurrence of the event despite having even previously been on corticosteroid treatment, acute drug-induced liver injury secondary to infliximab was deemed to be the most likely cause of his abnormal liver biochemical results.

\section{Outcome of liver injury management}

By the fourteenth week post-infliximab administration, serum ALT had gradually improved to $51 \mathrm{U} / \mathrm{L}$, AST to $53 \mathrm{U} / \mathrm{L}$, ALP to $506 \mathrm{U} / \mathrm{L}$, and total bilirubin to $2.2 \mathrm{mg} / \mathrm{dL}$ (Fig. 3; Fig. 4) with plans for periodic monitoring of liver enzymes. The patient's diarrhea symptoms completely resolved after the first infusion of infliximab.

\section{Discussion}

As ICPI therapies are being more frequently employed to treat many advanced cancers, hepatotoxicity is being recognized as one of the irAEs [1-13]. New elevation in liver transaminases during the ICPI treatment should prompt investigation of potential drug-induced liver injury. However, other co-existing conditions and/or infections that require additional medical treatments could also be associated with hepatotoxicity, the differential diagnosis toward the etiology may be confounding. This diagnostic challenge may be overcome by careful review and analysis of the history. Points of consideration include evaluation for acute viral hepatitides, autoimmune disease, alcohol-associated hepatitis, immune-related adverse event on the liver (especially given prior irAE associated with skin rash and colitis), and potentially infliximab-associated hepatitis.

Ipilimumab and nivolumab have been independently associated with the liver irAE [3-13]. The incidence of hepatoxicity for ipilimumab alone, for instance, was estimated to be $1.6-3.9 \%$ (ascertained by ALT elevations) in any grade of severity $[7,11]$. Grade 3 or 4 hepatotoxicity has an estimated 3-7\% incidence [3]. Recent data suggests an incidence of hepatotoxicity of as high as $11 \%$, with a reported fatality rate of $0.2 \%$ [13]. Liver injury as a result of exposure to ipilimumab usually occur after 2-4 cycles or a median time of 3-9 weeks after initiation of the drug, with potential to cause elevations in liver tests to reflect hepatocellular or mixed cholestatic injury [3-5]. Nivolumab may also cause hepatotoxicity, with onset of injury 2-6 cycles or 1-3 month after initiation 


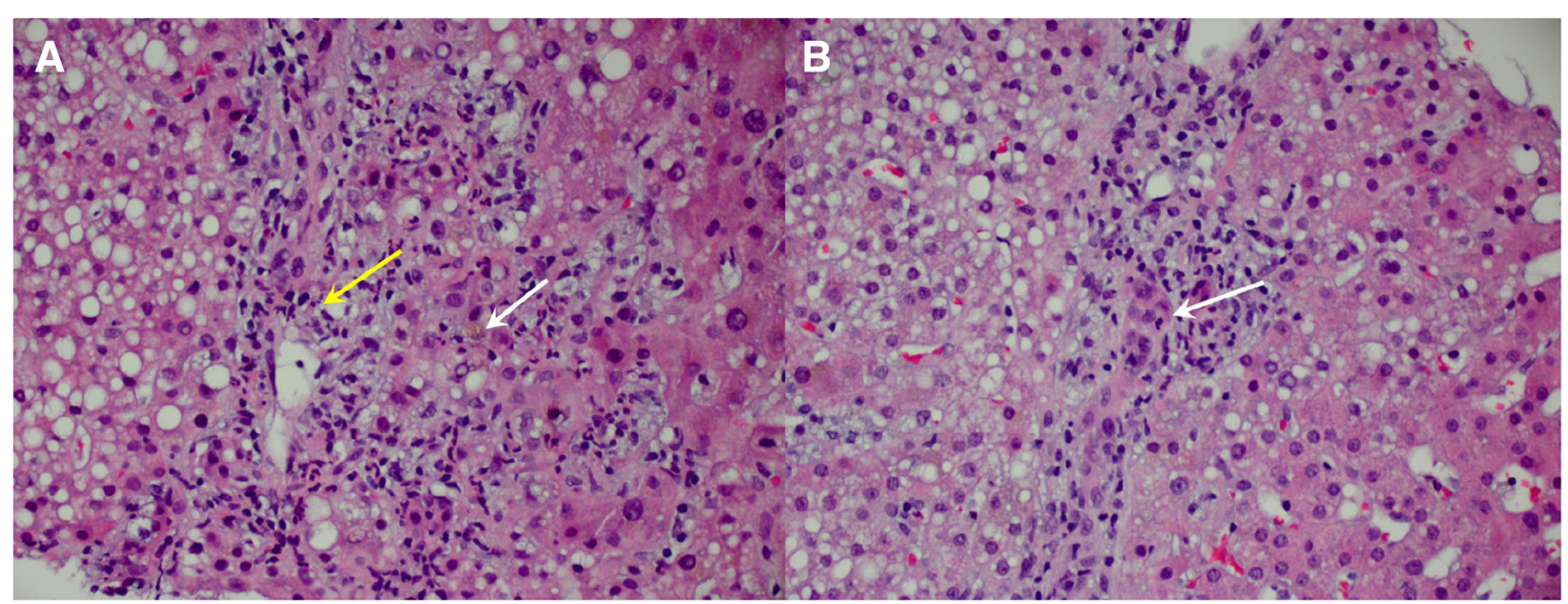

Fig. 5 Liver biopsy histology. Panel A: (Hematoxylin and eosin stain, 20x) Portal mixed inflammation (yellow arrow) and periportal cholestasis (white arrow). Panel B: (Hematoxylin and eosin stain, 20x) Bile ductular injury or cholangitis

of treatment [6]. The incidence of ALT elevations from nivolumab alone is estimated to be up to $3.8 \%$ in any grade of severity, based on clinical trial data [7]. The pattern of liver injury from nivolumab resembles that from ipilimumab. Varied findings may result on abdominal imaging of the liver (CT or ultrasound) from normal findings to mild hepatomegaly, periportal edema, and low-attenuation of the liver parenchyma [14]. Combination therapy utilizing both a CTLA-4 inhibitor and PD-1 inhibitor have been applied towards advanced melanoma treatment and is also being explored in other cancers at the expense of higher risk for $\operatorname{irAE}[15,16]$. Recent data estimates hepatotoxicity from combined therapy to be about $13 \%$ with median time to onset of about 2.1 months [13]. Prior clinical trial data had suggested the overall incidence of ALT elevations in combined therapy to be as high as $17.6 \%$ [7]. Hepatocellular and/or cholestatic liver injury patterns may be seen [17]. There is no compelling relationship between the autoimmune antibodies and autoimmune liver disease $[5,17,18]$.

Histopathological findings of ICPI-related hepatitis had been reported previously. Such features included: lymphohistiocytic inflammation with interface hepatitis, eosinophilic infiltration or acidophil bodies, granulomas, perisinusoidal fibrosis, periportal fibrosis, and/or biliary ductal injury [9, 14, 17, 33]. While there is no known pathognomonic histologic finding to distinguish ICPI-related hepatitis from histologic findings generally seen in drug-induced liver injury (DILI), granulomas, with or without fibrin deposits, and variable presence of plasma cells, continue to be characterized in more recent cases of ICPI-related hepatitis [17].

The current standard initial treatment for ICPI-related hepatitis is immunosuppressive therapy with high-dose corticosteroids such as methylprednisolone or prednisone
$[7,8,11,16,17]$. In a recent study, few patients were documented to have achieved spontaneous remission without corticosteroid therapy [17].

Infliximab is an anti-TNF- $\alpha$ inhibitor that has been well-studied in treating inflammatory bowel disease. Published reports of its application in this context were reported since 2006 [19], and subsequent applications of its use to treat ipilimumab-induced colitis followed [20-24], where infliximab has demonstrated efficacy in providing prompt remission in diarrhea symptoms. Infliximab-associated liver injury remains a potential concern in such patients [25-30]. The incidence of infliximab-associated liver injury was estimated to be $0.68-0.83 \%$ in prior studies examining DILI $[29,30]$. This adverse effect may present in several potential forms: hepatocellular injury; cholestatic liver injury, autoimmune-like, or reactivation of viral hepatitis B $[26,28,31,32]$. Unless jaundice manifests, cases are generally asymptomatic. Liver enzymes are generally monitored periodically while on infliximab therapy.

Despite alcohol use and prior administration of three cycles of ipilimumab and nivolumab, this particular patient's liver biochemical profile was unremarkable and stable 4 months after initiation of the immune agents. The first sign of ALT elevation occurred only 6 days after the first infusion of infliximab and had increased six-fold by 4 weeks. Hepatitis occurred despite being on prior steroid therapy prescribed for his treatment of colitis. A brief period of high-dose intravenous steroids for presumed ICPI-related hepatitis did not improve the liver enzymes elevation. Overall, ALT levels remained significantly elevated above $200 \mathrm{U} / \mathrm{L}$ until 8 weeks post-infusion of infliximab when ALT levels began to decline. There was a mixed cholestatic pattern of liver injury with peak alkaline phosphatase levels as high as $1852 \mathrm{U} / \mathrm{L}$ by 8 weeks post-infusion, and direct hyperbilirubinemia 
with total bilirubin as high as $20.7 \mathrm{mg} / \mathrm{dL}$ by 7 weeks post-infusion. This patient did not have hepatitis B infection nor develop any pertinent autoimmune markers. Although EBV and CMV DNA PCR were not specifically tested, the patient's clinical condition did not eventually worsen in the absence of antiviral therapy, despite the new addition of immunosuppressive therapy.

Cases of ICPI-associated hepatitis, $\mathrm{AIH}$, and other forms of DILI were compared in a previous histologic study that suggested expectation of less confluent necrosis compared to both AIH and DILI, less plasmacytosis compared to $\mathrm{AIH}$, and less eosinophilic infiltration than in DILI, but no difference in portal tract inflammation [9]. The liver biopsy of this patient revealed inflammatory infiltrates attributed to acute hepatitis, whereas findings of steatosis and mild fibrosis may be related to subtle chronic liver disease in the setting of chronic alcohol use. Since the current liver histologic knowledge was insufficient to differentiate ICPI-associated liver injury from other forms of DILI, additional understanding of the pathophysiology of irAE in conjunction with the analysis of the clinical timeline led to a clinical judgment towards attribution of the patient's liver injury to infliximab exposure.

\section{Conclusion}

Diarrhea is a well-known side effect of ICPIs that often requires the use of steroids to induce remission. In steroid-refractory cases, biologic agents such as infliximab have been increasingly employed with good therapeutic effect. Since future patients are likely to encounter such a clinical scenario, hepatotoxicity from infliximab must be carefully monitored. The differential of acute liver injury in this patient population will become more expansive. Therefore, careful evaluation of the pharmacologic chronology and prompt exclusion of other potential acute liver disease, including acute viral hepatitis and immune-related liver injury, are important. While liver histology itself may not necessarily distinguish the causative agent, it may help exclude other known forms of liver disease and assess the degree of liver injury.

\section{Acknowledgements \\ None \\ Funding \\ This study was not supported by any funding.}

\section{Availability of data and materials}

The datasets used and analyzed during the current study are available from the corresponding author on reasonable request.

\section{Authors' contributions}

YW was the senior author of this study, developed the concept, designed the study, interpreted the results, ensured that the accuracy and integrity of the data was preserved at all stages, agreed to be accountable for all aspects of this study, and contributed to the writing of the manuscript with input from all authors. $\mathrm{HZ}$ collected the data for the study, and wrote the manuscript. WL reviewed the pathology slides, collected pathology data and revised the final manuscript. All authors read and approved the final manuscript.

\section{Ethics approval and consent to participate}

The ethics approval of this study was granted by the IRB committee at the University of Texas MD Anderson Cancer Center (PA18-0472). The consent was waived for this study.

\section{Consent for publication}

Not applicable

\section{Competing interests}

The authors declare that they have no competing interests.

\section{Publisher's Note}

Springer Nature remains neutral with regard to jurisdictional claims in published maps and institutional affiliations.

\section{Author details}

${ }^{1}$ Division of Gastroenterology, Hepatology and Nutrition, The University of Texas Health Science Center at Houston, Houston, TX 77030, USA.

${ }^{2}$ Department of Pathology/Laboratory Medicine, The University of Texas MD Anderson Cancer Center, Houston, TX 77030, USA. ${ }^{3}$ Department of Gastroenterology, Hepatology and Nutrition, The University of Texas MD Anderson Cancer Center, 1515 Holcombe Blvd., Unit 1466, Houston, TX 77030, USA.

Received: 10 August 2018 Accepted: 11 February 2019

Published online: 18 February 2019

\section{References}

1. Lemech C, Arkenau HT. Novel treatments for metastatic cutaneous melanoma and the management of emergent toxicities. Clin Med Insights Oncol. 2012;6:53-66

2. Reese Z, Straubhar A, Pal SK, Agarwal N. Ipilimumab in the treatment of prostate cancer. Future Oncol. 2015;11(1):27-37.

3. Weber JS, Kähler KC, Hauschild A. Management of immune-related adverse events and kinetics of response with ipilimumab. J Clin Oncol. 2012;30(21): 2691-7.

4. Weber JS, Dummer R, de Pril V, Lebbé C, Hodi FS, MDX010-20 Investigators. Patterns of onset and resolution of immune-related adverse events of special interest with ipilimumab: detailed safety analysis from a phase 3 trial in patients with advanced melanoma. Cancer. 2013;119(9):1675-82.

5. National Institutes of Health. LiverTox: Clinical and Research Information on Drug-Induced Liver Injury. Ipilimumab. 2018. https://livertox.nIm.nih.gov/ Ipilimumab.htm. Accessed 6 Aug 2018.

6. National Institutes of Health. LiverTox: Clinical and Research Information on Drug-Induced Liver Injury. Nivolumab. 2018. https://livertox.nIm.nih.gov/ Nivolumab.htm. Accessed 6 Aug 2018.

7. Weber JS, Postow M, Lao CD, Schadendorf D. Management of Adverse Events Following Treatment with Anti-Programmed Death-1 agents. Oncologist. 2016;21(10):1230-40.

8. DeSouza K, Savva C. Management of Immunotherapy Related Adverse Effects. J Cancer Prev Curr Res. 2016:6(1):00187.

9. Zen Y, Yeh MM. Hepatotoxicity of immune checkpoint inhibitors: a histology study of seven cases in comparison with autoimmune hepatitis and idiosyncratic drug-induced liver injury. Mod Pathol. 2018;31(6):965-73.

10. Ibrahim RA, Berman DM, DePril V, et al. Ipilimumab safety profile: summary of findings from completed trials in advanced melanoma. J Clin Oncol. 2011;29(15_suppl):8583.

11. Linardou $H$, Gogas $H$. Toxicity management of immunotherapy for patients with metastatic melanoma. Ann Transl Med. 2016;4(14):272.

12. Michot JM, Bigenwald C, Champiat S, et al. Immune-related adverse events with immune checkpoint blockade: a comprehensive review. Eur J Cancer. 2016:54:139-48.

13. Suzman DL, Pelosof $L$, Rosenberg A, Avigan Ml. Hepatotoxicity of immune checkpoint inhibitors: an evolving picture of risk associated with a vital class of immunotherapy agents. Liver Int. 2018;38(6):976-87. 
14. Kim KW, et al. Ipilimumab associated hepatitis: imaging and clinicopathologic findings. Investig New Drugs. 2013;31(4):1071-7.

15. Rotte A, Jin JY, Lemaire V. Mechanistic overview of immune checkpoints to support the rational design of their combinations in cancer immunotherapy. Ann Oncol. 2018;29(1):71-83.

16. Puzanov I, Diab A, Abdallah $\mathrm{K}$, et al. Managing toxicities associated with immune checkpoint inhibitors: consensus recommendations from the Society for Immunotherapy of Cancer (SITC) toxicity management working group. J Immunother Cancer. 2017;5(1):95.

17. De Martin E, Michot JM, Papouin B, et al. Characterization of liver injury induced by cancer immunotherapy using immune checkpoint inhibitors. Hepatol. 2018;68(6):1181-90.

18. Teply BA, Lipson EJ. Identification and management of toxicities from immune checkpoint-blocking drugs. Oncology (Williston Park). 2014; 28(Suppl 3):30-8.

19. Beck KE, Blansfield JA, Tran KQ, et al. Enterocolitis in patients with Cancer after antibody blockade of cytotoxic T-lymphocyte-associated antigen 4. J Clin Oncol. 2006;24(15):2283-9.

20. Lord JD, Hackman RC, Moklebust A, Thompson JA, Higano CS, Chielens D, et al. Refractory colitis following anti-CTLA4 antibody therapy: analysis of mucosal FOXP3+ T cells. Dig Dis Sci. 2010;55:1396-405.

21. Johnston RL, Lutzky J, Chodhry A, Barkin JS. Cytotoxic T-lymphocyte associated antigen 4 antibody-induced colitis and its management with infliximab. Dig Dis Sci. 2009;54:2538-40.

22. Phan GQ, Weber JS, Sondak VK. CTLA-4 blockade with monoclonal antibodies in patients with metastatic cancer: surgical issues. Ann Surg Oncol. 2008;15:3014-21.

23. Minor DR, Chin K, Kashani-Sabet M. Infliximab in the treatment of antiCTLA4 antibody (ipilimumab) induced immune-related colitis. Cancer Biother Radiopharm. 2009;24:321-5.

24. Pagès $\mathrm{C}$, Gornet JM, Monsel $\mathrm{G}$, et al. Ipilimumab-induced acute severe colitis treated by infliximab. Melanoma Res. 2013;23(3):227-30.

25. Rossi RE, Parisi I, Despott EJ, et al. Anti-tumour necrosis factor agent and liver injury: literature review, recommendations for management. World J Gastroenterol. 2014:20(46):17352-9.

26. Mancini S, Amorotti E, Vecchio S, Ponz de Leon M, Roncucci L. Infliximabrelated hepatitis: discussion of a case and review of the literature. Intern Emerg Med. 2010;5(3):193-200.

27. Parisi I, O'Beirne J, Rossi RE, et al. Elevated liver enzymes in inflammatory bowel disease: the role and safety of infliximab. Eur J Gastroenterol Hepatol. 2016;28(7):786-91.

28. National Institutes of Health. LiverTox: Clinical and Research Information on Drug-Induced Liver Injury. Infliximab. 2018. https://livertox.nIm.nih.gov/ Infliximab.htm. Accessed 6 Aug 2018.

29. Björnsson ES, Bergmann OM, Björnsson HK, Kvaran RB, Olafsson S. Incidence, presentation, and outcomes in patients with drug-induced liver injury in the general population of Iceland. Gastroenterology. 2013;144(7):1419-25.

30. Björnsson ES, Gunnarsson BI, Gröndal G, Jonasson JG, Einarsdottir R, Ludviksson BR, et al. Risk of drug-induced liver injury from tumor necrosis factor antagonists. Clin Gastroenterol Hepatol. 2015;13(3):602-8.

31. Esteve M, Saro C, González-Huix F, Suarez F, Forné M, Viver JM. Chronic hepatitis B reactivation following infliximab therapy in Crohn's disease patients: need for primary prophylaxis. Gut. 2004;53(9):1363-5.

32. van Casteren-Messidoro C, Prins G, van Tilburg A, Zelinkova Z, Schouten J, de Man R. Autoimmune hepatitis following treatment with infliximab for inflammatory bowel disease. J Crohns Colitis. 2012;6(5):630-1.

33. Kleiner DE, Berman D. Pathologic changes in ipilimumab-related hepatitis in patients with metastatic melanoma. Dig Dis Sci. 2012;57(8):2233-40.

\section{Ready to submit your research? Choose BMC and benefit from:}

- fast, convenient online submission

- thorough peer review by experienced researchers in your field

- rapid publication on acceptance

- support for research data, including large and complex data types

- gold Open Access which fosters wider collaboration and increased citations

- maximum visibility for your research: over $100 \mathrm{M}$ website views per year

At BMC, research is always in progress.

Learn more biomedcentral.com/submissions 